\title{
Intravitreal triamcinolone acetonide for treatment of resistant and persistent diabetic macular edema
}

\author{
Hazem Azab M.D. \\ Giza Memorial Institute, Ophthalmology Teaching Hospital, Giza, Egypt. \\ E-mail:hazemazab2@gmail.com \\ Maged Adly Naguib M.D. \\ Giza Memorial Institute, Ophthalmology Teaching Hospital, Giza, Egypt. \\ E-mail:drmagedadly@yahoo.com
}

Received: 16 July 2019/ Accepted 17 Sept. 2019 / Publication date: 20 Oct. 2019

\begin{abstract}
Purpose: The purpose of this study was to evaluate the outcome of intravitreal triamcinolone acetonide in diabetic macular edema, refractory cases. Patients and Methods: A retrospective study of forty eyes diagnosed clinically and supported with optical coherence tomography with diabetic macular edema were than $300 \mathrm{~m}$ in thickness. All eyes were injected with a single injection preservative free triamcinolone acetonide $(4 \mathrm{mg} / 0.1 \mathrm{ml})$. Patients were subjected to visual acuity and optical coherence tomography on each follow up visit which was continued for mean eight months.

Results: The mean central subfield thickness at baseline was $504 \mathrm{~m}$, at five weeks. The mean central subfield thickness dropped by about $195 \mathrm{~m}$ and baseline visual acuity $0.8 \log$ MAR unit was improved by $0.02 \log$ MAR unit from baseline that were recorded in $17(42.5 \%)$ eyes, $11(27.5 \%)$ eyes improved in central subfield thickness without improved vision, $5(12.5 \%)$ eyes more worse than before injection and lastly $7(17.5 \%)$ eyes without changes in central subfield thickness or visual acuity. Conclusion: triamcinolone acetonide is safe, effective and promising therapy in resistant and persistent diabetic macular edema.
\end{abstract}

Keywords: triamcinolone acetonide is safe, effective and promising therapy in resistant and persistent diabetic macular edema.

\section{Introduction}

Diabetic macular edema (DME) is the most common cause of disturbed central vision in diabetic retinopathy (DR). Visual acuity (V.A.) and macular thickness are two important parameters in follow up of patients with DME (Fursova et al., 2017). Recent studies have shown intravitreal triamcinolone acetonide injection (IVTAI) to be an effective treatment for DME (Alhinai et al., 2017), although antivascular endothelial growth factors (VEGF) agents are generally used as first line treatment for patients with DME (Bressler et al., 2009). Corticosteroid may be especially useful in pseduophakic patients poorly responsive to anti - VEGF therapies (Omay et al., 2016). Wisconsin epidemiological study of diabetic retinopathy (DR) states the 10years cumulative incidence of DME to be $20.1 \%$ among type - I DM and 25.4 among those with type II DM (Ip, 2008). Duration of DM, poor glycemic control, hypertension, pregnancy, nephropathy, hyperlipidemia, obesity and anemia are known risk factors of D.M. In chronic and sever cases, fluid leakage is associated with accumulation of lipid in the outer plexiform layer (Fursova et al., 2017). Steroid stabilized the blood retinal barrier, regulate expression of VEGF and inhibit pre inflammatory factor, other action of steroid include expression of inflammatory pigment epthelium derived factor inhibiting the expression of matrix metallo protinses and adhesion molecules on vascular endothelial cells, all such action stabilize the basement membrane and reduce permeability - related exudation (Wykoff , 2017). The use of steroid for treatment of DME has been strong anti inflammatory and out edema properties, effect of steroid is reducing VEGF expression, leukocytosis and inflammatory cytokine production (Lee and Olk, 1991).

Corresponding Author: Hazem Azab M.D., Giza Memorial Institute, Ophthalmology Teaching Hospital, Giza, Egypt. E-mail: hazemazab2@gmail.com 


\section{Patients and Methods}

A retrospective analysis $(2017-2018)$ of 28 patients, 40eyes with DME was undertaken at Memorial institute of ophthalmological Research, Giza and Elnour eye hospital, Giza. Sixteen (57.1\%) patients were male and twelve (42.8\%). All patients had pre, and post injection measurement of DME using zeiss - cirrus optical coherence tomography (OCT). $4 \mathrm{mg} / 0.1 \mathrm{ml}$ of preservative free. Triamcinolone actonide (TA) was used for (IVTAI). The main outcome parameter were effect on macular edema and change in best corrected visual acuity (B.C.V.A.).

\section{Inclusion criteria:}

1- Age more than 25 years.

2- DME refractory to anti - VEGF and laser photocoagulation.

3- CST more than 350 um.

4- No prior IVTAI within 6 months (Ms).

5- No prior ocular laser of any sort within 3 Ms of injection.

6- No prior of intraocular surgery within $6 \mathrm{Ms}$ of IVTAI.

\section{Exclusion criteria:}

1- No subretinal or preretinal fibrosis.

2- No intraocular surgery in the study eye for the last $6 \mathrm{Ms}$.

3- History of ocular inflammations.

4- Glaucoma.

5- Steroid responsive patients.

6- Patients and drugs that can be associated with risk of developing macular edema such as prostaglandine analogs, anti-neoplastic agent. Vision was measured in $\log$ MAR units from ETDRS digital chart while CST was taken as reference macular thickness as it represents the subfoveal factor edema which is most common factor for reduced vision in DME. Follow up period for all cases means $8 \mathrm{Ms}(6-12 \mathrm{Ms})$.

\section{Results}

The total numbers of IVTAI given was 28 patients with 40 eyes included $12.0(42,8 \%)$ patients bilaterality, mean age of the patients was 55 ys. (28-70ys), $16(54.1 \%)$ male and $12(42.8 \%)$ female. 11 (39.2\%) with type - I DM and 17 (60.7\%) patients, type - II DM. The mean CST at baseline (on the day and before giving IVTAI was $520.7 \mathrm{~m}$ (Fig - 1) at 5 weeks, the means CST dropped by $195 \mathrm{~m}$ at 17 (42.5\%) eyes (Fig. 2), at 6 Ms follow up mean CST reductions had increased by $80.5 \mathrm{~m}$ from 6 weeks level, however, the 6 Ms follow up mean CST reduction was $275.5 \mathrm{~m}$ less than mean baseline thickness, (Fig. 3).

At three weeks after IVTAI, the mean visual acuity had dropped by a just $0.01 \log$ MAR units, (po.862) at 6 Ms follow up V.A. improved by $0.02 \log$ MAR units from baseline (P - 0.418). All over one year follow up (mean $6 \mathrm{Ms})$, BCVA was improved in $17(42.5 \%)$ eyes greater than $20 / 40(0.03$ $\log$ MAR units were than 5 line letters). 9 (22.5\%) eyes decreased (improved) in CST without improved in vision, 6 (15\%) eyes without improvement in CST and V.A. and lastly $8(20 \%)$ eyes were deterioration than before with progress visual loss and increased in CST. Lastly after more than $6 \mathrm{Ms}, 6$ eyes of (14 improved eyes) were deteriorated with recurrent sever DME and visual loss more than 4 lines of litters (less than 20/400). 

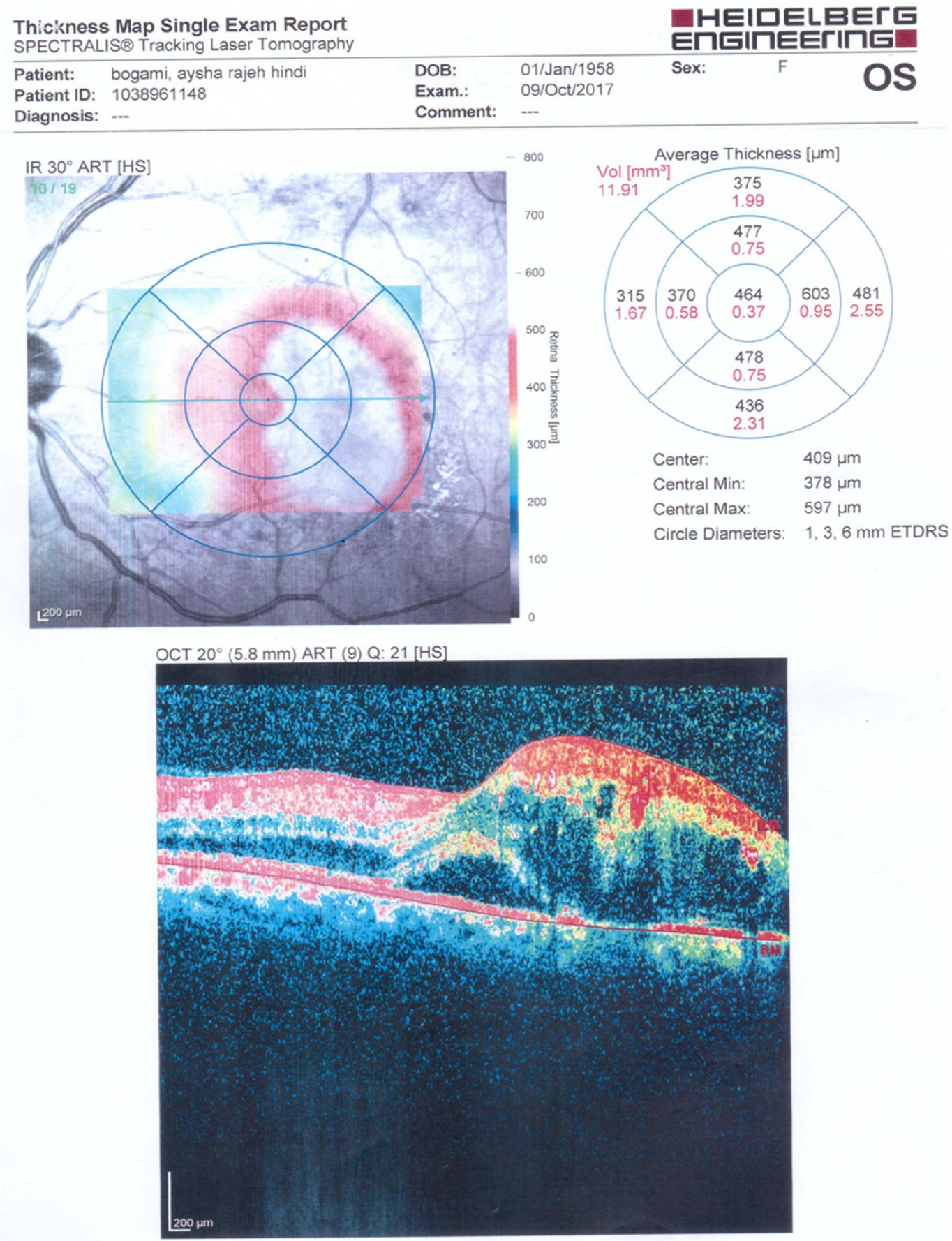

\begin{tabular}{llll|}
\hline Notes: & $0 / 10 / 7 / 7$ & \\
Date: $25 / 10 / 2018$ & Signature: & Thickness Map Single Exam Report
\end{tabular}

Fig. 1: Severe macular edema 
Thickness Map Single Exam Report SPECTRALIS $\otimes$ Tracking Laser Tomography

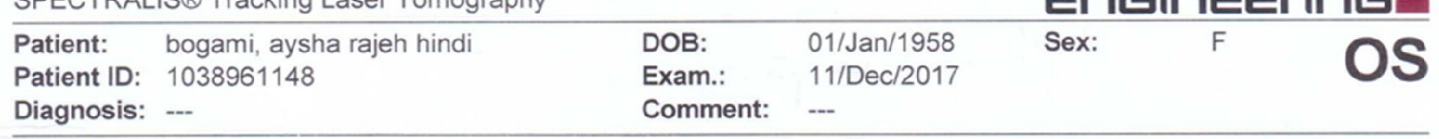
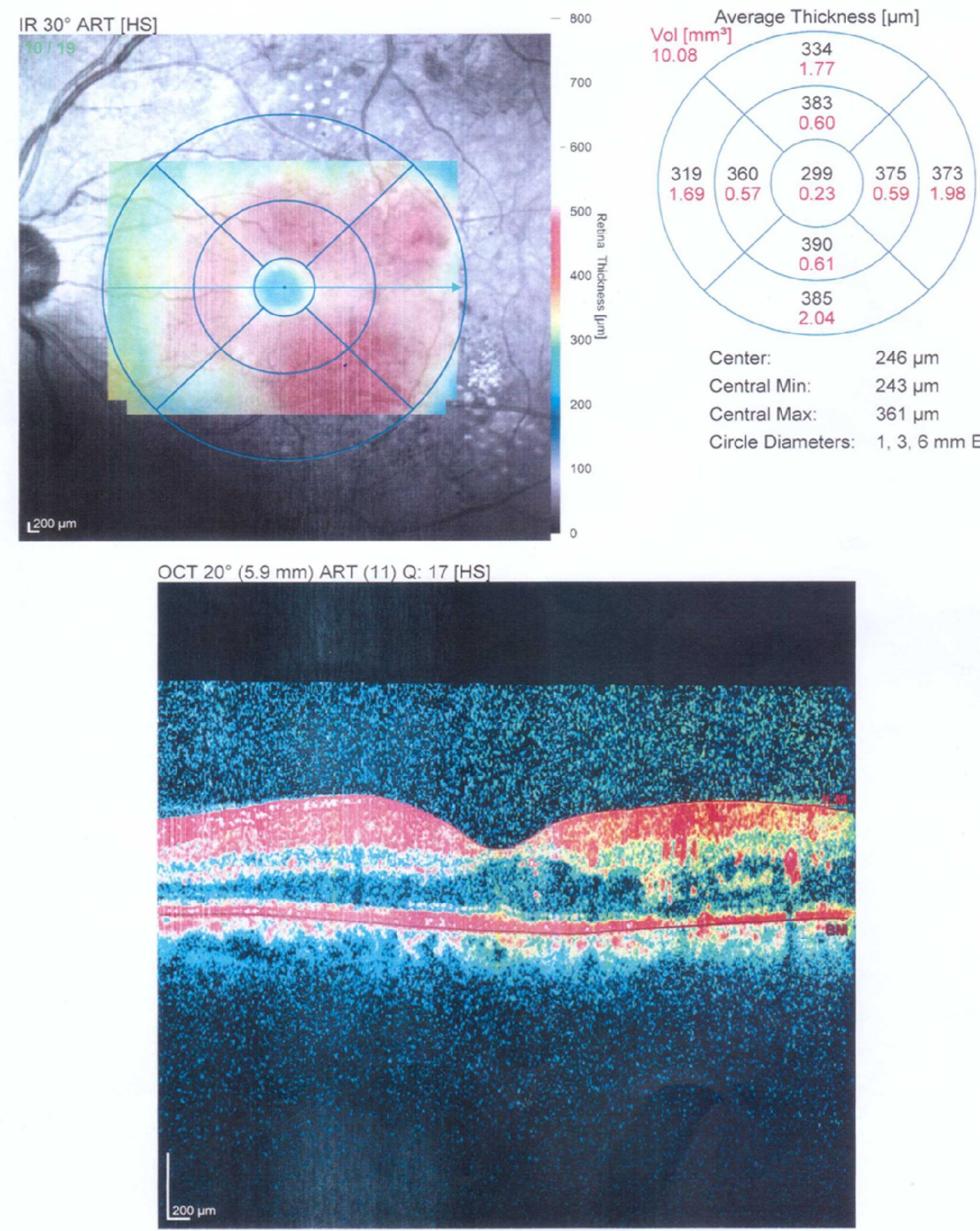

Fig. 2: Improved macular edema 

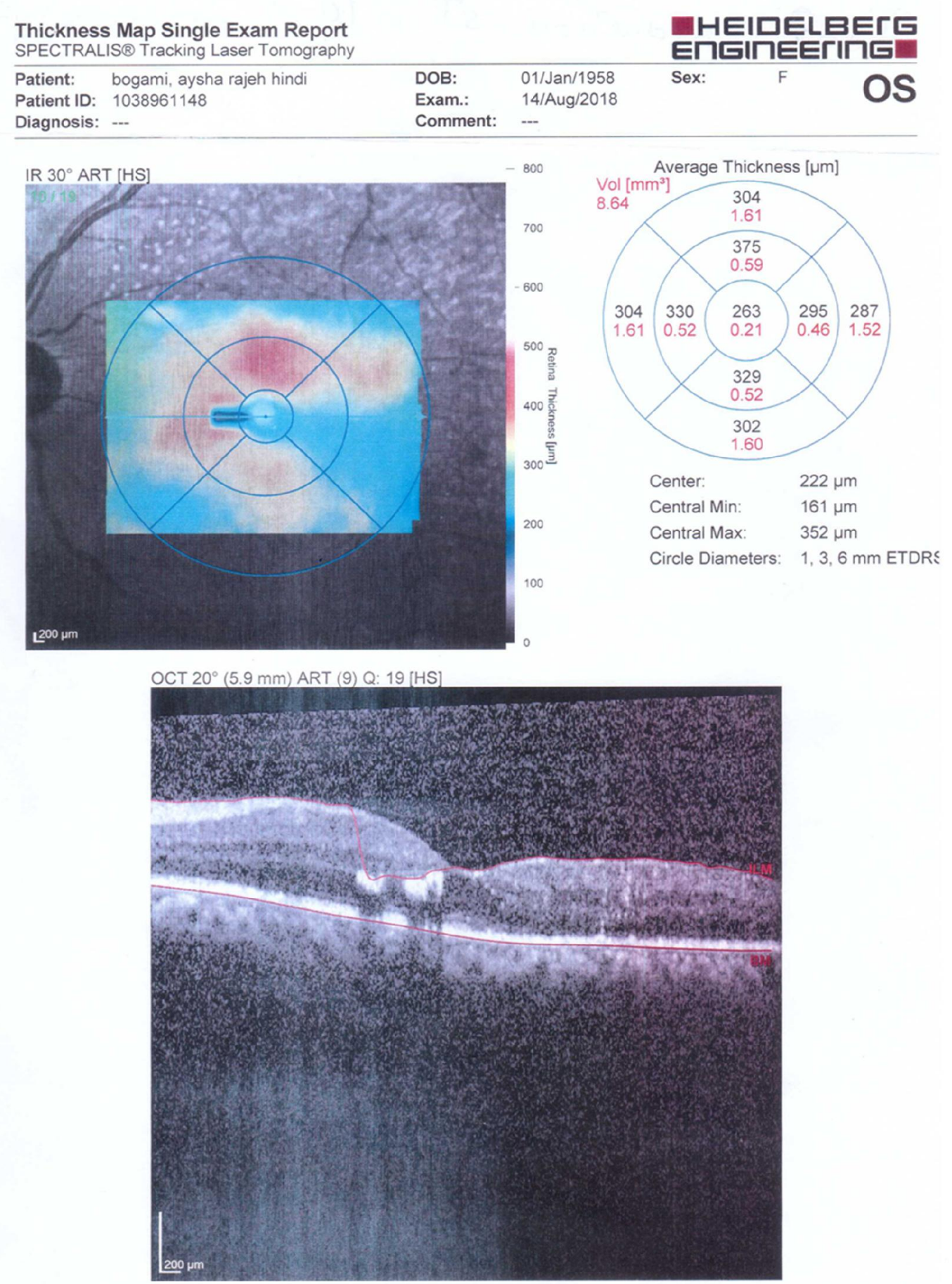

\begin{tabular}{lll|}
\hline Notes: & $/ 4 / 18 / / 8$ \\
\hline Date: $25 / 10 / 2018$ & Signature: & \\
\hline Software Version: 6.8 .3 & www.Heidelbergengineering.com & Thickness Map Single Exam Report
\end{tabular}

Fig. 3: Healed macular edema 


\section{Discussion}

Diabetic macular edema remain an important cause of visual loss, although anti - VEGF agent are generally used as first line treatment for patients with DME (Karst et al., 2018; Tomic et al., 2017) focal and grid laser photocoagulation had remain the standard line of treatment in DME, however in majority of patients, the V.A. remain unchanged $(60.9 \%)$ or even become worst $(24.6 \%)$ ؛ only $14.5 \%$ showed improvement (Lee and Olk, 1991). TA is a synthetic steroid of the glucocorticoid family, $4.0 \mathrm{mg}$ of IVTAI yields enough concentration to give therapeutic effect for approximately 3 Ms (Romero-Aroca et al., 2016).

Karst et al. (2018) have compared $1-4 \mathrm{mg}$ TA to laser photocoagulation and found greater improvement in mean BCVA with laser at 2 years compared to TA group, however Lam et al. (2007) found no statically significant difference between laser and TA at 6 Ms follow up.

Overall line major group American, European, Canadian, International council of ophthalmology and Asia Pacific have laid down guidelines for treatment of DME has shifted from laser to anti - VEGA (Diabetic Retinopathy, 2011). In most instances and resistant DME was advised for IVTAI but does carry a list of potential risks such as high ocular tension, cataract, endophthlimits, retinal tears or detachment and hemorrhage (Chu et al., 2008; Omay et al., 2016). The outcome in our study, all cases (40 eyes) received IVTAI with persistant and resistant DME more than $6 \mathrm{Ms}$, the mean CST at baseline was $504.6 \mathrm{~m}$, at 6 weeks follow up the mean CST dropped by $195 \mathrm{~m}$ and with end $3 \mathrm{Ms}$, increased CST reduction by $80.5 \mathrm{~m}$ less than baseline thickness in 17.0, eyes recording $42.5 \%$. all over one year follow up (mean $6 \mathrm{Ms}$ ), BCVA was improved in $17(42,5)$ eyes to $0.2 \mathrm{log}$ MAR units, 9 (22.5) eyes with improved CST but without improved vision. 6 eyes (15\%) without improved in CST or vision and $8(20 \%)$ eyes were deteriorated and progresses vision loss with increases in CST ( $6+8$ eyes) $25 \%$, that is secondary to ischemic changes. Following up 6 Ms follow up, 6 eyes $15 \%$ from 17 improved eyes (35.2\%) with recurrent DME and loss of vision. This cases management by high dose $16.0 \mathrm{mg} 0.1 \mathrm{ml} \mathrm{TA}$. Wykoff, (2017) published, high dose of TA has more sustained effect on V.A. and CST without retinotoxic effect. The longest term data available for $4 \mathrm{mg}$ TA in refractory DME came free study done by Romero et al. (2016) in this paper have giving a preliminary analysis at $3 \mathrm{Ms}$ was effective in improving V.A. and reduce macular thickness for $87 \%$ of eyes and showed 55\% gain V.A. and $126 \mathrm{~m}$ improvement in macular thickness from baseline. Ahmed et al. recorded V.A. improved in $47 \%$ eyes, dropped from baseline in $35 \%$ eyes and remain unchanged in $18 \%$ eyes.

After one year follow up 16 eyes (40\%) with improvement) in CST and V.A. anatomically and functionally, $12(30 \%)$ improved anatomically without functionally and $12(30 \%)$ eyes not improved automatically or functionally and 12 eyes not improved at all.

Finally IVTAI advised for persistanal and resistant DME following non response for anti VEGF, however IVTAI considered from my study as a prolonged lifespain for long time as possible as, (regress cases about $60 \%$ that's secondary to progressive ischemic and degenerative changes). Lastly, the combination of anti-VEGF and macular laser photocoagulation is considered the standard of care for treatment of patients with DME, however intravitreal steroid injections results as a therapeutic options for management of DME especially as an additional choice in pseudophakic patients and patients previously treated with anti - VEGF agent, laser and vitrectomy with poor results.

\section{References}

Alhinai, A., U. K. Wali, T. Abdul Rasoal and S.G. Rizvi, 2017. Experience of intravitreal triamcinolon acetonide for treatment of diabetic macular edema among Omani population. Oman Journal of ophthalmology, 10(3):177-183.

Bressler, N.M., A.R. Edwards, R.W. Beck, C.J, Flaxel A.R. Glassman, et al., 2009. Exploratory analysis of diabetic retinopathy Progression through 3 years in a randomized clinical trial that compares intravitreal triamcinolone acetonide with focal grid photocoagulation. Arch ophthalmol., 124: 1566 - 71 .

Chu, Y.k., E.J. Chung, O.W. Kown, et al., 2008. Objective evaluation of cataract progression associated with a high dose intravitreal triamcinolon injection Eye, 22 (4): 895 - 899. 
Diabetic Retinopathy Clinical Research Network, 2011. Writing committee, Aiello Lp, Beck RW, Bressler NM, Browning $\mathrm{Dj}$, Chalam KV, et al. Rational for the diabetic retinopathy clinical research network treatment protocol for center involved diabetic macular edema. Ophthalmology, 118(12):e5-14. doi: 10.1016/j.ophtha.2011.09.058.

Fursova, A.Z., N.V. Chubar', M.S. Tarasov, I.F. Saifullina and G.G., Pustovaya, 2017. Clinical associations between photoreceptor status and visual outcomes in diabetic macular edema. Vestn Oftalmol., 133(1):11-18.

Ip, M.S., S.B. Bressler, A.N. Antoszyk, C.J. Flexel, J.E. Kim, S.M. Friedman, et al., 2008. A randomized trial comparing intravitreal triamcinolone and focal / grid photocoagulation for diabetic macular edema: Baseline features. Retina, 28, 919-30.

Karst, S.G., J. Lammer, C. Mitsch, M. Schober, J. Mehta, C. Scholda, et al., 2018. Detailed analysis of retinal morphology in patients with diabetic macular edema (DME) randomized to ranibizumab or triamcinolone treatment. Graefes Arch Clin Exp Ophthalmol., 256(1):49-58.

Lam, D.S.C., C.K.M. Chan, S. Mohamed, T.Y.Y. Lai, V.Y.W. Lee, D.T. Liu, et al., 2007. Intravitreal triamcin olone plus sequential grid laser versus triamcinolone or laser alone for treating diabetic macular edema: Six month outcomes. Opthalmology, 114(12): 2161-2167.

Lee, C.M. and R.J. Olk, 1991. Modified grid laser photocoagulation for diffuse diabetic macular edema. Long - term visual results, Ophthalmology, 98: 1594 - 602.

Omay, E., U. Elgin, E. Sen andP. Yilmazbas, 2016. The early effects of intravitreal antivascular endothelial growth factor agents on intraocular pressure and central corneal thickness. Int Ophthalmol, 36: 665-670.

Romero-Aroca, P., M. Baget-Bernaldiz, A. Pareja-Rios, M. Lopez-Galvez, R. Navarro-Gil and R. Verges, 2016. Diabetic Macular Edema Pathophysiology: Vasogenic versus Inflammatory. J Diabetes Res., 2016:2156273.

Tomic, M., R. Vrabec, T. Poljicanin, S. Ljubic and L. Duvnjak, 2017. Diabetic macular edema: traditional and novel treatment. Acta Clin Croat., 56(1):124-32.

Wykoff, C.C., 2017. Impact of intravitreal pharmacotherapies including antivascular endothelial growth factor and corticosteroid agents on diabetic retinopathy. Curr Opin Ophthalmol., 28(3):213-218. 